\title{
E.A. Tinyakova
}

\section{Professional Ethics for Business Relations}

\begin{abstract}
The article on professional ethics in business is partly review type and classifying different approaches. Classic and non-classic approaches in professional ethics are characterized. The influence of philosophical branches on the content of professional ethics is shown. This way of presenting material has been chosen by the author with the aim to emphasize the most problematic and difficult points in contemporary professional ethics, particularly accountants'. Ethical considerations are psychologically grounded in some respects. The main notions of professional ethics are presented with the aim of concretisizing their content. The focuses for building professional ethics have been chosen: interaction of oppositions, social conditions of acceleration, creativity, emphasis of individual realization, respect. The most difficult problem has been pointed out: eternal moral stability and dynamic on-going of our life which demands the decision of a moment. Overwording in description of business relation is marked as a negative trait: all situations in professional ethics can't be described. The specific traits of accountants 'profession are underlined. Further prospects of discussing professional ethics are planned. The conclusions serve the respect of human labour and its quality.

Key words: Philosophical ethics, professional ethics, the good, the evil, casuistics, labour quality, discipline, accountant, psychology, moral.
\end{abstract}

$\mathrm{T}$

here are two words for labeling «correctness and order» in human relations in business: «ethics» (of Greek origin) and «moral» (of Latin origin). They are partly synonyms, but etimologically «ethics» suits better, because in ancient Greek «ethos» went from surroundings to men (that is why the word directed men to adapt themselves to the world around them). The Latin word «moral» went from men to surroundings, emphasizing human will. «Moral» is more straightforward in meaning. The etimological difference between these words reflects the basic and cardinal problem in business ethics: how to achieve balance between men and economic environment requirements; but this dialogue has a tendency to show disbalance to human relations, it happens because ethics (with its abstract notions) becomes more and more complicated and confused by psychology.

TINYAKOVA, Elena Aleksandrovna - PhD, Department of Humanities disciplines, Sergiev Posad Institute for the Humanities, SPF Moscow Institute of Business and Law. SPF Moscow University Witte. 141300, Moscow region. Sergiev Posad, Moscow Highway 12-A.

[etinyakova@bk.ru] 
Aristotle, the famous Greek philosopher, interpreted «ethics' as practical philosophy». He forsaw that ethics would be backgrounded by psychology. Lorenzo Valla, the Italian philosophy of the 15-th century, stated that ethics is born by human nature [1], but not descends from the heaven as they thought in Antique times.

We may point out two different approaches to ethics, professional ethics included: 1.classic and 2. non-classic. The first approach develops from the ancient past and tries to make equal the words «ethics» and «wisdom». The classic approach gives recommendations to follow the right and best ways in life: the justice stands above human relations and people came to the idea that to get justice one must suffer, the just result may appear after human death. The second approach, «non-classic», is due to philosophy of post-modernism and psychology, having discovered numerous variants in realizing one's charachter. It doesn't give strict recommendations, but cares mostly that a person should find oneself in a favourable situation. Pragmatism, utilitarism and psychology urged and helped «non-classic» approach. Here suits the branch of philosophical ethics — "casuistics' (from the Latin word «casus», «case» in English) «ethics for an hour». Its recommendations may contradict classic ethics, but in many respects they help to get a profit for an applicant. Casuistics may also be called «short-term ethics» in comparison with philosophical ethics that is «long-term». But since it is an ethical branch, casuistics shouldn't destroy the ethical moral laws, for example let the evil take the upper hand over the good. Casuistics is more life-like sometimes because not a single man has ever been born perfect, everybody makes one's path in life though mistakes. The paradoxical tragedy of human psychic is that one realizes one's mistakes after having done a certain action. There is a sad proverb: we begin to cry after we have lost something: the loss makes us recognize the value and need of the thing lost. Such situations come often in professional ethics.
The problem of professional ethics, from the point of view of casuistics, is to correct professional mistakes but not to put a person in an uncorrectable situation. The wisdom of professional ethics is to give everybody a chance to correct one's mistake and protect from repeating it. The more wise the correction of a professional mistake is, the more is the chance that it will never come again. That is why casuistics seems more real than classic professional ethics which rejects any chance of error - everything should always be correct.

Nowadays there often appear tension between the essence and the obligatory. The more so as social acceleration, stated by contemporary sociology, sharpens the situation: we have less time to think over our decisions than in the 20-th century. And from the point of view of psychology, lack of time presses psychic and adds to anxiety and worry. In ancient antiquity (the 6-th century BC) Greek philosophers paid a special attention to the use of time [ «Appreciate time», Hilon; «Everything has its time», - Pittak; "What is the wisest? - Time because it guides everything» — Phales]. Thus the root of motivating business relations has become very complicated: it has at least a four-fold projection-basic reasons (derived from the content of an economic situation per se); the atmosphere in the company or working group; exterior influence [Thomas Donaldson analyses the social contrast between society and business; 2] and the person, focusing the whole situation. Nowadays it is just the fourth component that demands most numerous considerations and causes the uoverwording» of professional ethics [3] as a subject, and it just complicates the matter.

Specialists in ethics know the golden rule of ethics: "Treat other people as you like to be treated yourself». Philosophy of the basic ethical rule is more often referred to the Bible, to I. Kant or Confucius. Folklore philosophy of various peoples emphasizes the «effect of echo» in human relations. Let's special consider the recommendations of wisdom in proverbs $[4 ; 5]$. From the original roots proverbs are considered to advise always that is right and just. The same can 
be said about philosophical aphorisms. As an example we shall citate the following: «Energy and persistence conquer all things» [Benjamin Franklin], «A friendship founded on business is better than a business founded on friendship» [John D. Rockefeller], «Everybody is ambitious. The question is whether he is ambitious to be or ambitious to do»[JJean Monnet],» The higher the culture is the more labour is estimated [Georg Friedrich Wilhelm Roscher], «Our respect to the general moral rules is just the conception of duty» [Adam Smith]. The difference between a proverb and an aphorism is that the first one vectors life as a whole and the second one vectors numerous situations of the same kind.

But we may give situations from life as examples, when we lose happiness while following a proverb. For example, there are many proverbs in various folklores which recommend to tell only the truth, to help all people without doubt. But each of us can give illustrations when these proverbs may lead us to deadlocks or an unhappy hour. The philosophical root of this situation is as follows: the conceptions of the good and the evil and their following variants are quite clear in human mind, but our life is so dynamic, that it destroys the mental borders. Here the philosophical phrase may help: «Extremes meet» (or in everyday speech we often say: «Contradictions often add each other»)). And it is just non-classic ethics, that has come to help in such situations. We have come to the dilemma: in difficult professional situations what should we obey: a) the moral truth; or b) the situation. The answer is: one must be very wise to adapt the situations to the moral truth.

It is necessary to add here a psychological tint to the considerations: not a single case in professional ethics can't be understood as static; the situations are always dynamic in its development, one must catch the most favorable moment in its on-going and put it at the basis of ethical decisions. Sometimes we must pay more attention to the past, sometimes to the future, but one ought to be very responsible in one's decisions. Hamlet's question «To be or not to be» is the eternal source of ethics. Here we may join the motto of ancient Greek medicine which laid the background of wisdom (by the way more connected with human health than today): «Don't make harm». Together with Hamlet's question the ancient Greek motto will lead the right path in professional ethics.

Ethics as a discipline and research has basic notions; rules, norms, principles, categories, values $[6 ; 7]$, beliefs, religious systems. All these notions are aimed at creating objectivity, stability of human relations, our considerations, business relations and decisions. Stability, which can't be interrupted, is achieved if business relations serve goodwill, but paradox works when the evil takes the upper hand in business relations and evil-doers get an enjoyable life. The famous Russian philosopher N. Berdyaev said that the «best suffer more than the worst» [8;9]. Of course, his philosophical path touched Christian philosophy, the sufferings of Jesus Christ, who suffered for mankind. But we shouldn't be too one-sided in considering this huge problem. Within the frames of human life it does really happen that the evil wins, this is the tragedy of human existence, but in eternity the good is always the winner. This abstract position, substantially raised above human existence, is cardinal for further content of the article $[10 ; 11]$.

Now let's consider the guiding notions mentioned. «Rules» are worked out to unite people socially with the goal of rationality acceptable for most people to let matters go on without obstacles. From the point of view of high ethics rules may have some pragmatic decisions which are aimed not at the perfectness of man but at convenience in relations. Rules help to build a whole social organism and protect from unnecessary steps. Rules are more professional in content in comparison with norms. Norms take more time to be formulated and keep the on-going of human life through years; mainly they are common to different professions. Principles are developed from norms but they are rather individual in content. We may define principles as an individual approach to combin- 
ing rules and norms. Though some people may share the same principles. These are just principles that make and help conscience meet obligations. The German philosopher I. Kant [12] developped «the ethics of duty». Some thinkers criticized him that he deprived people of freedom: in his conception a person should always follow the fulfillment of demands set to him. But from the other point of view the German philosopher granted freedom, removing unavoidable and accidental situations through fulfillment of a duty. If a situation sets a demand, then it is better to cope with it than to try to ignore and leave it a persistent unfulfilled component of activity. The other German philosopher Arthur Schopenhauer proclaimed:

«Human will rules the world» (his work «Die Welt als Wille und Vorstellung»). It is wise to keep to the» golden balance» of these two philosophical positions. But human will shouldn't distort goodwill. Here it is wise to recollect the Italian philosopher Niccolo di Bernardo dei Machiavelli: «The goal, set, justifies the means applied». The philosophy of this phrase follows two main paths: the good and the evil, and with the development of human activity they stand further and further from each other.

Categories are theoretical notions and make up an abstract matrix of our professional life [6;7]. The basic categories of ethics are «the good», «the evil», duty, eternity, enjoyment, justice, peace, struggle, harmony, anarchy, etc. The categories of ethics, professional ethics included, follow the principle of dichotomy; they make a system of oppositions. One of the cores of these oppositions are I. Kant's antinomies [13]. That is why we can make a conclusion: human ethics is constant struggle between its dichotomies. Combining oppositions in professional ethics has become the most acute problem nowadays. Contemporary science has also this kind of problem: contradictory opinions often exist side by side (for example in theoretical physis recognition and denying of reason). Some theoreticians of science state that science has vanished. But this situation has nothing common with scepticism. It will be a great mistake if we take a skeptical approach to combining ethical oppositions and setting them on the same level. The evil is always evil, and the good is always good. The difference that can't be denied is: the good is constructing happiness and the evil is constructing sorrow. But there may appear opponents, that will say: «Conceptions of happiness are also contradictory». As one of the ways to decide this discussion the possible answer will come: «The good tries to keep the dear from vanishing».

Values and beliefs are sure to help in border like, unstable ethical situations. They refer to philosophical ethics. Different professions have values that meet: responsibility, accuracy, industry, patience, professional competence, rhythm in activity, liability to contacts (a certain level of sociability). If we remove one profession from another in professional ethics, we may lose moral traits what so ever. A human being stands at the basis of every profession. And the more so as animals are coming nearer and nearer to human relations, business included. But this new problem of professional ethics is just being opened and demands a separate space for consideration. Nowadays professional values are backgrounded by safe and sound way of life. Professional ethics is becoming deeper and deeper not only psychological, but also biological. Professional difficulties may distract a person from observing necessary rules of keeping healthy. Good moral can't be built on the basis of destroyed health (here evil skills and habits are meant). Values help every person to realize his (or her) sociality in full without disturbing others if we act within commonly shared values. But there are also values, thanks to which various professions differ. These values are connected with the best traits of this or that profession. Let's compare the profession of an accountant and an artist. These are opposite professions in content. The creativity of an artist develops overcoming the ordinary rules. But an accountant should keep an eye on the obligatory and the ordinary. Here a question may arise; is the profession of an accountant devoid of creativity? We shall make a mistake 
if we answer «no». In accounting we deal with another type of creativity - «to find the best way to fulfil the professional duty» (this is the universal definition of creativity). Analysis of creativity can be a strong moral source of professional ethics. Creativity is the most emotionally saturated trait of professional ethics. It is connected with such problems of professional ethics: development of initiative, partnership between the leader and other collegues, keeping traditions and moving forward, adaptation of new personell, etc. Creativity can help to develop synergetic level (it can be a separate problem of professional ethics to be discussed) in business relations, in other words, to reach self-regulation, minimizing orders and commands. Sometimes strict discipline is considered as dictatorship, but strictness may be of different types: it may serve the authority of a leader or the clearness of business communication. In the second case it is sure to help creativity. Here we shall mark a very important line of consideration about business ethics — business communication on the level of language use (the author hopes to discuss it on the pages of the journal in the future). Drawbacks and defects in language use may turn professional ethics upside down. We shall search for moral decision, but the root of disorder should be found just in imperfect use of language. The profession of an accountant is partly protected from this problem because in this profession a figure or number stand higher a word very often.

We shall go on with analyzing ethical notions. Beliefs are closely connected with traditions and have a certain amount of specifically national world outlook. Beliefs are connected with culture type and may have mystic or fatal components. They are more often specifically cultural than values. The most wide-spread beliefs in professional ethics are beliefs in good luck. It is good when such beliefs are play like, but if they take a stiff form or a norm they may do harm to relations and bring a negative psychological effect, because mystic ideas are stronger than logical behaviour.
Philosophical ethics, and professional ethics as part of it, have ties with religious systems. But it is a separate huge problem to be discussed. The best classical variant of professional ethics, relating to protestant religion, was developed by Max Weber, the German sociologist [14]. He puts such qualities at the basis of business ethics: duty, industry, rational attitude to money.

Before passing over to regarding ethics of an accountant we shall mention the eternal moral dilemmas:

$\checkmark$ relation of aims and means of their fulfillment;

$\checkmark$ relation of individual and social interests;

$\checkmark$ choice between short-term profit and long-term results;

$\checkmark$ relation of material and spiritual values while making decisions.

The aspects of professional ethics in horizontal and vertical projections look as follows. In horizontal projection the main problems are connected with interrelation of persons mainly of the same professional position. The favorable decision of these problems makes a fertile soil for professional relations. In vertical projection the main problems are connected with building a ladder of relations: the hierarchy of professional relations should be observed but the observation should admit initiatives from downward to upward and from upward to downward (the leader should adapt the initiatives to individual acceptance by the staff and at the same time inspire the staff to develop their own initiatives; a good will combines obedience and creativity among the staff. The more so as creativity is a very popular problem in contemporary professional ethics, and many times it focuses the rest of professional problems. Creativity is connected with realization of an individuality. We may explain the psychological need of this situation. Any profession, that of an accountant as well, is loaded with a huge potential of information (we are living in society of information, mainly thanks to computer technologies), and creativity gives a certain amount of psychological relaxation: human psychology has a trait to get accustomed to repeated steps and there 
appears mood of tiredness, monotony. New ideas bring freshness in relations.

Now we shall pass over to professional ethics of an accountant particularly. The main professional activity of an accountant is calculations. The activity demands such cognitive abilities as classifying, summarizing and interpreting of financial results [15]. The profession of an accountant has much mechanical in process, great responsibility in presenting calculations. They often say that an accountant has a «feel» for figures; it means that an accountant should make his conscience psychologically 'mathematical») that is all mental operations depend on figures; figures dominate above words as has been stated earlier. Inaccuracies are excluded, of course this creates a certain tension in the profession of an accountant: justifying with words is not admitted. Still creativity is not excluded, but has a specific interpretation. For example, shortening of mathematical calculations at the expense of very fast oral calculations mainly. But the desire to do calculations without mistakes and have some superior checking causes dependence of accountants on mechanical or computer calculators. An analytical mind is typical of an accountant, it means that all professional operations are measured by calculating. The volume of analytical mental work is rather great in accounting profession: a specialist should handle masses of details without losing perspective. This appreciation of accuracy and a sense of order can lower and sometimes exhaust the emotional sphere. The answer to a professional question is always inevitable: we repeat-figures rule the mind. Such professional situation makes emotional sphere to a certain extent mechanical, but the successful end of numerous calculations returns the blocked psychological energy. n conclusion, let's choose the background for abundant and learned discussions and research in professional ethics: «What is difficult? - To get to know oneself. What is easy? - To give advice to others»». - Phales, the ancient Greek philosopher. Michel de Montaigne, the famous French humanist and jurist, kept on to the end of his life making additions to his main work «Essais»; he researched the dialogue between the law, predominantly on the moral level, and the realization of a man in life. His major conclusions was: it is impossible to get rid of misdoings and drawbacks in life, but human mistakes should serve perfection and development [16]. M. Montaigne left precept to modern French philosophers Jacques Lacan (psychoanalysis) and Lyotard (postmodernism, conception of narrotology) $[17 ; 18]$. The French philosopher criticizes metanarrotology which claims to unique truth and justice, thus it is connected with power. The author of the article doesn't mean in the least to crush the logically framed moral matrixes in numerous books on professional ethics, which sometimes build the ideal professional space, but unpredictiveness of human psychic should be taken into consideration. The second substantial factor is the socio-psychological situation in society. D. Anderson, a contemporary American sociologist, builds such consequence: diversity of society through tolerance should lead to respect [19]. By respect he does not necessarily mean «acceptance» or «agreement» but « treating people as if their integrity were equal to yours». G. Leech regards professional relations still finer: tact, generosity, approbation, modesty, agreement, sympathy [20]. $\mathrm{R}$. Audi builds his conception of understanding professional relations by means of «play of words»: «business ethics and ethical business» [21], here we find the unity of professional competence and moral. Really the high quality of performing a job often causes adoration, however high competence often removes borders of the possibilities of human psychic, overtiredness and exhaustion may begin to distort character and psychic. This factor, by the way, is very significant for accountants' profession. The pressing through objectivity of accountants' calculations can make impossible to observe professional rules in relations; derangement, frustration and failure may follow. That is why for the profession of an accountant relaxation has a specific moral significance. 


\section{References:}

1. Valla, L. 1989. On the true and the false good. Freedom of will. M.: Nauka. $474 \mathrm{~s}$.

2. England, L. 2001.Why discuss international business ethics? Journal «English Teaching Forum» (USA) 2(39):40-46.

3. Jill, P. 2009. A New Zealand Study Ethical Issues and Workplace Problems in Commercial Hospitality.

4. Mitin, I.E. Russian proverbs and their English counterparts. M.: Karo, 2009.

5. Collis, H. 101 American English proverbs. Publ. by Passport Books, NTC/ Contemporary Publishing Group Inc., 1992.

6. Izza, M. Ethics. In Principles of Taxation FA2012. Study manual. Ed. By ICAEW. Printed in the United Kingdom by Polestar Wheatons, 2013. P. 229-249.

7. Izza, M. Ethics,sustainability and corporate responsibility. In Business Strategy. Study manual. Ed. By ICAEW.Printed in the United Kingdom by Polestar Wheatons, 2013. P. 571-603.

8. Motroshilova, N.V. The meaning of creativity. Russian thinkers and philosophy of the West. M.: The Republic, 2006. S. 233-242.

9. Berdyaev, N.A. On ierarahii values. Goals and means. Selected works. Rostov-n/D: «Phoenix», 1997. S. 247-257.

10. Eternity. Philosophical Dictionary Vladimir Solovyov / cost. G.V. Belyaev. Rostov-n/D: «Phoenix», 1997. S. 28-29.

11. Evil. Philosophical Dictionary Vladimir Solovyov / cost. G.V. Belyaev. Rostov- n/D: «Phoenix», 1997. S. 137.

12. Kant. Philosophical Dictionary Vladimir Solovyov / cost. GV Belyaev. Rostov-n/D: «Phoenix», 1997. S. 184-187.

13. Antinomy. Philosophical Dictionary Vladimir Solovyov / cost. G.V. Belyaev. Rostovn/D: «Phoenix», 1997. S. 180-181.

14. Weber M. The Protestant Ethic and the Spirit of Capitalism. M., 2003.

15. Pshegusova, G.S., Andreeva L.L., Grebennikova N.D., Mlodinskaya N.V. English for economic specialties: a textbook. ed. 20. M.: «Darya, and K», 2013. S. 67-69.

16. Montaigne, M. Experiments. M.: AST. Astrel, 2011. 768 s.

17. Lyotard, J.F. La Condition Postmoderne. Paris, 1979.

18. Lyotard, J.F. Des dispositifs pulsionnels. Paris, 1980.

19. Anderson, D. 1999. The keys to a civil Society. Journal «English Teaching Forum» (USA). 4(37). P. 36-48.

20. Leech 2005. Politeness: Is there an English-West Divide? In Journal of Foreign Languages. General Serial. №160. № 6.

21. Audi, R. 2008. Business Ethics and Ethical Business. OZON.RU. 